DEMOGRAPHIC RESEARCH

VOLUME 40, ARTICLE 51, PAGES 1501-1528

PUBLISHED 18 JUNE 2019

https://www.demographic-research.org/Volumes/Vol40/51/

DOI: 10.4054/DemRes.2019.40.51

Research Article

Parental leave policies and continued childbearing in Iceland, Norway, and Sweden

Ann-Zofie Duvander

Trude Lappegård

Synøve N. Andersen

Ólöf Garðarsdóttir

Gerda Neyer

Ida Viklund

(C) 2019 Ann-Zofie Duvander et al.

This open-access work is published under the terms of the Creative Commons Attribution 3.0 Germany (CC BY 3.0 DE), which permits use, reproduction, and distribution in any medium, provided the original author(s) and source are given credit.

See https://creativecommons.org/licenses/by/3.0/de/legalcode. 


\section{Contents}

1 Introduction 1502

2 Background 1505

3 The three countries 1506

4 Expectations 1510

$5 \quad$ Data and methods $\quad 1512$

6 Results 1513

7 Discussion 1518

8 Acknowledgements 1521

$\begin{array}{ll}\text { References } & 1522\end{array}$

$\begin{array}{ll}\text { Appendix } & 1528\end{array}$ 


\title{
Parental leave policies and continued childbearing in Iceland, Norway, and Sweden
}

\author{
Ann-Zofie Duvander ${ }^{1}$ \\ Trude Lappegård ${ }^{2}$ \\ Synøve N. Andersen ${ }^{3}$ \\ Ólöf Garðarsdóttir ${ }^{4}$ \\ Gerda Neyer ${ }^{5}$ \\ Ida Viklund ${ }^{6}$
}

\begin{abstract}
BACKGROUND

Demographic theories maintain that family policies that support gender equality may lead to higher fertility levels in postindustrial societies. This phenomenon is often exemplified by the situation in the Nordic countries. These countries have parental leave policies that promote a gender-equal work-care balance for both parents, and these countries have comparatively high fertility levels. However, very little is known about the association between these policies and childbearing at the individual level.

\section{OBJECTIVE}

We explore how fathers' parental leave use is related to subsequent childbearing in Iceland, Norway, and Sweden, and we examine whether differences exist in childbearing outcomes among fathers who use no leave, those who use only the leave allocated to them by the policy, and those who use more than that amount of leave.

\section{METHODS}

The study is based on 15 years of administrative register data on parental leave use in Iceland, Norway, and Sweden. Event history analysis is used to follow parental couples

\footnotetext{
${ }^{1}$ Department of Sociology, Stockholm University, Sweden. Email: ann-zofie.duvander@sociology.su.se.

${ }^{2}$ Department of Sociology and Human Geography, University of Oslo, Norway. Email: trude.lappegard@sosgeo.uio.no.

${ }^{3}$ Statistics Norway, Oslo, Norway. Email: synove.andersen@ssb.no.

${ }^{4}$ University of Iceland, Reykjavík, Iceland. Email: olofgard@hi.is.

${ }^{5}$ Department of Sociology, Stockholm University, Sweden. Email: gerda.neyer@sociology.su.se.

${ }^{6}$ Department of Sociology, Stockholm University, Sweden. Email: ida.viklund@sociology.su.se.
} 
from the end of the parental leave use for their first or second child until a new birth takes place.

\section{RESULTS}

There is a positive association between fathers' leave use and second births in all three countries, while there is a negative association between fathers' parental leave use and third births in Norway and Sweden. Taking more than the 'father's quota' does not consistently increase the second-birth intensities.

\section{CONCLUSIONS}

The two-child norm is closely connected to the norm of fathers being engaged in child rearing, while only a select group of fathers continue with a third child.

\section{CONTRIBUTION}

The study shows that the association between gender equality and fertility differs between countries and by the parity of the child. It also shows the need to differentiate between policy-induced gender-equal behavior and gender-egalitarian parenting.

\section{Introduction}

Many scholars have investigated the relationship between gender equality and fertility trends at the macro level (see for example McDonald 2000; Neyer 2003; Goldscheider, Bernhardt, and Lappegård 2015; Anderson and Kohler 2015; Esping-Andersen and Billari 2015). These studies have regularly confirmed that in postindustrial societies, greater gender equality is associated with higher fertility levels. They typically point to the Nordic countries as countries that have achieved both high degrees of gender equality in society and high fertility levels. The Nordic countries have been forerunners in promoting gender equality and in implementing policies that facilitate the workfamily balance for women and for men. However, the results of studies on the link between policies, gender equality, and fertility also show that this association is sensitive to which policies are included and how they are measured (see, for example, Gauthier and Hatzius 1997; Kalwij 2010; Luci-Greulich and Thévenon 2013; Billingsley and Ferrarini 2014). In this paper, we concentrate on one of the core fertility-related, gender-equality, and work-care policies, namely, parental leave. Parental leave policies have long been regarded as essential in shaping gender relationships and fertility outcomes (Kamerman and Kahn 1978). Their importance has recently been highlighted in theories of fertility development, and the results of empirical studies have underlined their significance for fertility (McDonald 2000; 
Neyer 2003; Goldscheider, Bernhardt, and Lappegård 2015; Oláh 2003; Oláh and Bernhardt 2008).

Regarding gender and fertility, special attention has been given to parental leave policies that aim at a gender-equal division of both childcare and labor market work and support what is often termed the earner-carer-model. Fertility theories propose that gender equality in the labor market and in the family is a precondition to retain fertility levels close to replacement level (McDonald 2000; Goldscheider, Bernhardt, and Lappegård 2015). The Nordic countries stand out, both because of their policies toward women and men in the labor market and because of their focus on fathers' participation in childcare (Hakovirta et al. 2015). In all Nordic countries, the parental leave benefits that parents receive during their leave replaces a large share of their previous income (between 70 and 100\%, see Blum, Koslowski, and Moss 2017). The Nordic countries were also the first countries in the world to introduce a 'father's quota,' that is, to reserve part of the parental leave for the father (often combined with a less-contested mother's quota). The specific aim of the quota was to encourage fathers' early involvement in childrearing, and it turned out to be a success (Arnalds, Eydal, and Gíslason 2011; Duvander and Johansson 2012; Dahl, Løken, and Mogstad 2014). The Nordic countries have approximately 20 years of experience with the father's quota, and the fathers' share of leave use is substantial by international standards. This leave usage and the comparatively high fertility rate in the Nordic countries are generally taken as a sign that greater gender equality in the family leads to higher fertility (McDonald 2000; Neyer 2003; Goldscheider, Bernhardt, and Lappegård 2015). However, what patterns lie behind the macro-level associations between gender equality and higher fertility in the Nordic countries? How does the association play out at the individual level? How is the father's quota related to subsequent childbearing? Is it truly the most gender-equal couples who have more children in these countries, as fertility theories suggest? Or is it those couples in which the father takes only the father's quota and who follow the parenting and gender norms proclaimed by the policy?

The aim of this study is to examine the association between individual fathers' use of parental leave and continued childbearing by investigating whether the use of only the father's quota or a more equal sharing of parental leave play out differently with respect to the couple's subsequent childbearing. We compare three Nordic countries: Iceland, Norway, and Sweden. These are the three Nordic countries that have had an established father's quota for a substantial period of time, whereas both Denmark and Finland have been less consistent in reserving part of the parental leave time for fathers (for country-specific details, see Hakovirta et al. 2015; Blum, Koslowski, and Moss 2017). 
Researchers have put forth several arguments for why a more gender-equal parental leave use would increase fertility. First, a more equal division of work in the household would ease women's burden of work in the home and thus enhance the compatibility of childrearing and female employment more than it would decrease men's work-family compatibility. Parental leave taken by the father can facilitate a faster return to work of the mother. Both would make it easier for women and couples to realize childbearing plans (Cooke 2004; Duvander and Andersson 2006; Neyer, Lappegård, and Vignoli 2013). Second, shared parental leave indicates a shared responsibility for childcare during the child's first year(s) and signals the father's commitment to share the care of children later in the child's life also (Duvander and Andersson 2006). The father may also have a positive experience in caring for a small child and thus become more inclined to have additional children. The opposite may also be true, of course, as any negative experiences resulting from this increased involvement may lead to declines in the desire for more children. We argue that the importance of each explanation of the association may be different in different contexts, for different birth orders, and for different lengths of the father's leave.

We furthermore believe that to assess the association between parental leave policies, gender equality, and fertility, one needs to distinguish between fathers who use only the reserved part of parental leave and fathers who share the leave more equally with the mother. The two forms of parental leave use differ not only in length: They also carry a different meaning. The quota signals the minimum time that a father should devote to caring for his child. It eases negotiations between the parents, and it strengthens a father's position vis-à-vis their employer. The existence of a quota raises the expectation that fathers take leave and that taking no leave may become a behavior that requires justification. Thus, a quota may be not only the first step to a more genderequal sharing of care, it may actually induce a new gender norm of parenting.

Taking more leave than the quota, and thus going beyond the norm set by the policy, may be a sign of the father's greater commitment to gender equality and to a truly gender-equal sharing of parenting responsibilities. It may also be that the mother insists on an equal sharing of the leave or that her work or other circumstances, e.g., lack of childcare, require that the father takes more than his reserved part of the leave. In any case, taking more leave than the quota is a less socially and normatively protected behavior than taking only the quota. The links to fertility may therefore differ by the type of leave (quota or not) and not only by the length of leave.

By distinguishing among nonusers, quota-users, and more-than-quota users, our study will provide new insights into whether and how the use of policies that explicitly aim at changing the gender roles in the family is related to continued childbearing in countries with different policy contexts and policy uptakes. As the leave lengths differ between the three countries, we used this strategy to group the fathers to be able to 
compare between countries. We assumed that even if the quotas are of different lengths and represent different shares of the total leave in the three countries, they convey a similar meaning in all three countries. This assumption enables us to assess the links between policies and continued childbearing and to examine this association for different levels of gender equality.

We will start with an overview of the connection between fertility and gender equality and then explain the details of the parental leave systems in Iceland, Norway, and Sweden. We elaborate on expectations before presenting our data and results. We conclude with a discussion of our findings.

\section{Background}

Our point of departure is two profound societal changes that have swept across Western countries: new gender practices and shifts in family dynamics. Gender practices in market work and unpaid work have changed over the past decades, and in most Western countries there has been a move from a traditionally strict male-breadwinner model toward various degrees of dual-earner models in which women and men participate in the labor market. However, changes in employment have been more profound than changes in domestic responsibilities. This uneven development has been labeled the 'stalled revolution,' that is, women increasingly share the market work with men, but men have not to the same extent increased their share of domestic work (Hochschild 1989; England 2010; Stanfors and Goldscheider 2017). This situation is still found in the Nordic countries, even though men in these countries share more domestic responsibilities than in most other countries (Hook 2006). A relevant question today is whether we are on our way to the last phase of the gender revolution in which men share domestic work on equal terms (Goldscheider, Bernhardt, and Lappegård 2015). Important here is how we define the goal of gender equality and what level of sharing of labor (or leave) we refer to. Gender equality may mean a situation with no gendered economic or normative restrictions on the division of labor, which may, however, not necessarily result in a 50-50 division of all tasks.

The 'stalled revolution' is also assumed to have consequences regarding fertility. According to McDonald (2000, 2013), low fertility in certain countries today can be explained by the incoherence between the relatively high level of gender equity in individual-oriented institutions (i.e., the educational system and the labor market) and the low level of gender equity in the family and family-oriented institutions. Even though McDonald makes a distinction between gender equity (a concept indicating a sense of fairness) and gender equality in the sense of actually sharing - for example, sharing childcare half-and-half - his work is often cited in calls for family policies that 
support a gender-equal sharing of care. Many demographers and most gender and welfare state researchers share the view that fertility is affected by the conflicting realities and ideals in different institutions. They also point to the crucial role that family policies play in promoting or hampering progress toward greater gender equality in employment and care responsibilities and in shaping fertility patterns (Chesnais 1996; Daly 2000; Stier, Lewin-Epstein, and Braun 2001; Neyer 2003; Kalwij 2010; Thévenon and Gauthier 2011). However, studies on how the gender-equal use of such policies is connected to continued childbearing at the individual level are scarce. Although the few studies that exist find that mothers' childbearing intensities may be higher if the father takes some parental leave than if he takes none, the results on the link between a more gender-egalitarian sharing of parental leave and subsequent childbearing are not uniform. They vary by country, parity, duration of fathers' leave, time period, and strength of association. For instance, Duvander, Lappegård, and Andersson (2010) found that the fathers' leave is associated with continued childbearing more strongly in Norway than in Sweden. Using data from one decade earlier, Oláh (2003) found that the fathers' leave is associated with second births in Sweden, but that a similar measure gives nonconclusive results for Hungary. Moreover, there are studies indicating that the types of policies have different influences on fertility (Ang 2013; Cygan-Rehn 2016), and some have shown that mothers' use of leave has an influence on continued childbearing (for example Lalive and Zweimuller 2009; Matysiak and Szalma 2014). Studies on fathers' childcare and housework engagement, both obviously related to leave use, also indicate that engagement is

generally positively associated with continued fertility but to a different degree by context and socioeconomic group (Cooke 2004, 2009; Torr and Short 2004; Goldscheider, Bernhardt, and Brandén 2013; Nagase and Brinton 2017; Dommermuth, Hohmann-Marriott, and Lappegård 2017; Kato, Kumamaru, and Fukuda 2018). This finding raises further questions as to whether and to what extent the association between fathers' leave-taking and subsequent childbearing is shaped by the amount of sharing, the different norms of gender-equal parenting that the amount of sharing represents (policy-conforming vs. egalitarian), the configuration of the policies, the timing of the introduction and context of the policies, and the use of the policies with the first or a subsequent child.

\section{The three countries}

To isolate the effect of these differences in the policy setup and to scrutinize the individual-level associations between fathers' leave and fertility, we compare three countries that have similar policy aims but have policy constellations that are not 
identical. We believe that the association between fathers' care-taking and continued childbearing has to be studied in contexts where fathers participate in parental leave at a level that can be seen as more than a marginal phenomenon. In Iceland, Norway, and Sweden, fathers typically use substantial parts of their leave and have done so for quite some time (see Table 1). A father's quota was first introduced in Norway in 1993, in Sweden in 1995, and in Iceland between 2001 and 2003. When the reforms were implemented, the quota was 4 weeks in Norway and Sweden and 12 weeks in Iceland. Icelandic fathers used a third of the leave after the quota's introduction, but this share has declined after the economic crisis in 2008. Norwegian fathers' use has increased over time and today is over $15 \%$, while Swedish fathers use more than a fourth of all leave. As the total leave is of different lengths ( 9 months in Iceland, approximately 12 months in Norway and 16 months in Sweden), the various leave shares also imply various leave lengths. In all three countries the leave is job-protected, and in all countries the quota was introduced with the aim to promote gender equality.

In 1974, Sweden was first to introduce parental leave that could be used equally by mothers and fathers. The total leave length was then six months, and although the parental leave benefit was income-related, it was not seen as very plausible that many fathers would use the leave (Cedstrand 2011). Indeed, less than $1 \%$ of all leave days were used by fathers in the 1970s, but fathers' leave has increased slowly over time (Swedish Social Insurance Agency 2012). The total leave length was also extended over time, and in 1990 it was 15 months, whereof the income of 12 months was replaced at $90 \%$ of previous earnings, and three months at a low flat rate. The incomerelated compensation has since been approximately $80 \%$ of previous earnings, with a ceiling that affects mainly high-income fathers. The introduction of the reserved months of paid leave for fathers (father's quota) has had a major effect on fathers' leave use (Duvander and Johansson 2012), but even before the first reserved month was introduced in 1995, approximately half of all fathers used some parental leave. With the reform, usage increased to approximately nine out of ten fathers. The second reserved month introduced in 2002 was also parallel to an extension of the total leave to 16 months. From 2016, a third month of leave exclusively reserved for fathers was introduced, but this change is outside the scope of this study. 
Duvander et al.: Parental leave policies and continued childbearing in Iceland, Norway, and Sweden

Table 1: Characteristics of study populations of one- and two-child couples in Iceland, Norway, and Sweden, exposures of risk to a second and third birth, and distributions of months for each variable (percentages)

\begin{tabular}{|c|c|c|c|c|c|c|}
\hline & \multicolumn{2}{|l|}{ Iceland } & \multicolumn{2}{|l|}{ Norway } & \multicolumn{2}{|l|}{ Sweden } \\
\hline & $\begin{array}{l}\text { One-child } \\
\text { couples }\end{array}$ & $\begin{array}{l}\text { Two-child } \\
\text { couples }\end{array}$ & $\begin{array}{l}\text { One-child } \\
\text { couples }\end{array}$ & $\begin{array}{l}\text { Two-child } \\
\text { couples }\end{array}$ & $\begin{array}{l}\text { One-child } \\
\text { couples }\end{array}$ & $\begin{array}{l}\text { Two-child } \\
\text { couples }\end{array}$ \\
\hline \multicolumn{7}{|c|}{$\begin{array}{l}\text { Father's use of parental leave } \\
\text { during the first } 18 \text { months }\end{array}$} \\
\hline No use & 7.28 & 7.16 & 46.13 & 43.74 & 30.11 & 35.59 \\
\hline Up to quota & 72.19 & 76.36 & 35.64 & 37.68 & 37.18 & 37.53 \\
\hline More than quota & 20.03 & 16.48 & 18.23 & 18.59 & 32.71 & 26.88 \\
\hline \multicolumn{7}{|l|}{ Union status at birth } \\
\hline Cohabiting & 55.47 & 33.90 & 45.41 & 27.76 & 61.42 & 48.61 \\
\hline Married & 44.53 & 66.10 & 54.59 & 72.24 & 38.58 & 51.39 \\
\hline \multicolumn{7}{|l|}{ Time period at birth } \\
\hline $1994-1997^{1}$ & & & 31.84 & 34.85 & 21.60 & 4.60 \\
\hline $1998-2000$ & & & 21.63 & 24.18 & 19.96 & 26.31 \\
\hline 2001-2004 & 56.95 & 62.52 & 25.68 & 26.63 & 26.89 & 37.63 \\
\hline $2005-2009^{2}$ & 43.05 & 37.48 & 20.85 & 14.35 & 31.55 & 31.46 \\
\hline \multicolumn{7}{|l|}{ Mother's education } \\
\hline Low & 12.44 & 13.90 & 5.85 & 5.48 & 8.63 & 5.08 \\
\hline Medium & 24.74 & 23.10 & 52.23 & 53.73 & 52.98 & 54.08 \\
\hline High & 55.24 & 55.12 & 36.71 & 38.68 & 33.83 & 40.32 \\
\hline No information & 7.58 & 7.89 & 5.22 & 2.11 & 4.56 & 0.52 \\
\hline \multicolumn{7}{|l|}{ Father's education } \\
\hline Low & 15.11 & 15.07 & 7.85 & 7.39 & 10.75 & 7.83 \\
\hline Medium & 32.12 & 32.07 & 59.37 & 59.20 & 60.84 & 62.50 \\
\hline High & 38.85 & 41.03 & 29.51 & 31.90 & 24.96 & 29.22 \\
\hline No information & 12.92 & 11.84 & 3.27 & 1.51 & 3.45 & 0.44 \\
\hline \multicolumn{7}{|l|}{ Immigrant background } \\
\hline None born abroad & 85.84 & 90.83 & 80.43 & 84.95 & 73.09 & 82.87 \\
\hline Father born abroad & 2.49 & 2.06 & 5.06 & 4.32 & 6.50 & 5.22 \\
\hline Mother born abroad & 7.32 & 4.80 & 7.87 & 5.47 & 8.17 & 5.02 \\
\hline Both born abroad & 4.35 & 2.31 & 6.64 & 5.27 & 12.23 & 6.89 \\
\hline Mother's age (mean) & 27.3 & 30.7 & 28.5 & 30.7 & 28.8 & 30.9 \\
\hline Father's age (mean) & 30.0 & 33.2 & 31.8 & 33.5 & 31.3 & 33.1 \\
\hline Number of observations & 212,689 & 371,387 & $1,403,207$ & $3,151,932$ & 11.938 .958 & 15.227.927 \\
\hline
\end{tabular}

Note: ${ }^{1} 1995$ for Sweden. ${ }^{2} 2007$ for Norway.

Some important characteristics set the Swedish system apart from the others. Since 1995 parental leave has been defined in individual terms; half of the leave days are dedicated to the father and half to the mother. However, one parent can sign over days for the other parent to use (which is most often done from fathers to mothers). All days except the quota can be transferred. Another characteristic of the Swedish system is its flexibility. Paid and unpaid leave can be mixed and can be taken for part of a day. Paid leave can be used during the whole preschool period of the child (up to the child's 
eighth year). This flexibility results in great variation in total leave lengths and in the mothers' and fathers' leave lengths. Even though most leave is used during the first two years, some parents, especially fathers, use a fair share of their days during the child's later preschool years.

Norway gave fathers the right to childcare leave in 1977 and to parental leave in 1978. The Norwegian leave length was originally 18 weeks but has been extended over time, and the flexibility in the possibilities of use has increased somewhat, although not to the level of the Swedish system. Since the 1990s, the leave has been approximately one year, with the total number of weeks dependent on the preferred level of wage compensation ( $80 \%$ or $100 \%)$. In 2018 , the leave length was extended by an additional month. The major difference compared to the Swedish system is that leave eligibility depends on prebirth employment, with those ineligible for leave receiving a lump sum at birth. Around the turn of the century, approximately a fifth of all mothers received the lump sum payment (Duvander, Lappegård, and Andersson 2010). Moreover, the father's ability to use leave depends completely on the mother's eligibility. Since 2002, this requirement has been relaxed, but the father's quota still depends on the mother working. The Norwegian father's quota was introduced in 1993, and while very few fathers used any leave at the time of introduction, this percentage increased quickly from $4 \%$ just before the reform to $39 \%$ just after the reform (Cools, Fiva, and Kirkeboen 2015). However, very few fathers used more than the quota. Even if the Norwegian leave scheme is less strictly individual compared to the Swedish, the quota has been more radically expanded in steps from 2005 and onward: In 2005 to five weeks, in 2006 to six weeks, and in 2009 to ten weeks. Thereafter, it has been both expanded and reduced in steps, but since 2018 the father's quota has been 15 weeks.

Iceland is the latecomer in the Nordic paid parental leave setting, and until the late 1990s the scheme offered only childcare leave. The radical policy that provided three months to each parent and three months to share was introduced in steps between 2001 and 2003, making Iceland the leading country in terms of gender equality regulations. Moreover, the policy response was rather immediate. A great majority of all fathers use part of the leave and most use the full three months (Eydal and Gíslason 2015). Upon full implementation of the new law, eight out of ten fathers used at least three months of leave (Sigurdardóttir and Garðarsdóttir 2018). The wage compensation was $80 \%$ at the time of introduction, but it was reduced significantly in 2009 as a consequence of the economic crisis. This change reduced fathers' leave use (Sigurdardóttir and Garðarsdóttir 2018). The total leave length of nine months is not sufficient to cover the period up to the start of preschool, especially as it is not unusual for fathers to use leave at the same time as mothers, and other informal solutions are often sought for this childcare gap (Arnalds, Eydal, and Gíslason 2011). 
In all three countries, the father's quota has led to changed expectations of fathers; they are now much more expected to be involved, and there is a fairly stable norm for fathers to use the quota. In all three countries, the common pattern is for the father to be home on his own with the child for a period after the mother's leave when she has returned to work and before the child starts preschool (Duvander, Haas, and Thalberg 2017; Gíslason 2017; Kvande and Brandth 2017).

\section{Expectations}

Several explanations have been suggested for the relationship between a father's uptake of parental leave and subsequent childbearing. Some assume that more child-oriented fathers take parental leave and then go on to have more children. However, in those cases, the mothers often take less parental leave and may be more work-oriented and see one child as sufficient, which may offset the impact of the father's child orientation. Parental leave use itself may also influence the propensity to have another child. The influence can obviously be positive if the father and/or the mother were satisfied with the parental leave, or negative if they were not (Neyer, Lappegård, and Vignoli 2013).

These assumptions point to important selection issues, and to date very few studies have been able to disentangle selection from causality effects. Some studies have applied a difference-in-difference approach to estimate the effects of fathers' leave on various outcomes (see, for example, Lalive and Zweimuller 2009; Kotsadam and Finseraas 2013; Rege and Solli 2013). These studies deal with the selection issue in a more convincing way than purely correlational studies, but they also run the risk of not detecting effects that work gradually or in indirect ways. Gradual shifts and the spreading of new behaviors are hard to capture with the methods available. In this study, we expect that selection into leave and the effects from using the leave are interacting, and what we will measure is a combination.

By comparing countries with fairly similar policies and similar economic, social, and cultural conditions, we are better able to distinguish the impact of family policy on demographic behavior in the presence of other factors. First, following the theoretical arguments regarding gender equality in the family (McDonald 2000; Goldscheider, Bernhardt, and Lappegård 2015), our general expectation is that fathers' use of leave will increase the propensity of continued childbearing, but we need to make distinctions between: (1) the birth order of the child, (2) the level of fathers' leave use, (3) changes in associations over time, and (4) the country context. We expect a stronger association on the second child than the third, as there is a strong two-child preference and even norm in the Nordic countries; to have two children is expected and to have more is to make a family-oriented choice (Andersson et al. 2009). 
The macro-level association between greater gender equality and higher fertility would at the micro level mean that families in which the father takes more parental leave have a higher propensity for another child. The existence of a father's quota implies that using leave up to the quota and using more than that amount of leave indicate different behaviors. We assume that fathers who use the quota follow the policy-stipulated norm of behavior. Fathers who take more than the quota may be more child-prone and/or they may be more committed to sharing family responsibilities equally with their partner. We expect that fathers who use the quota and thus behave in a norm-conforming way have higher second-birth risks than fathers who take more than the quota (but both to have higher second-birth risks than fathers who take no parental leave). Regarding third-birth risk, it is certainly not seriously norm-breaking to have three children, but it often requires a more conscious decision. The associations may thus go both ways. It may be that the third-birth risk is higher for more-than-quota fathers because they are more committed to larger families, while 'only quota' users stop with fulfilling the two-child norm. The third-birth risk may also be lower because this may indicate couples in which the mother is more work-committed. Taking care of two children clearly implies more work than having one child.

We also expect the association between fathers' leave-taking and continued childbearing to change over time. The effect at the beginning of the policy implementation may have been that fathers using the leave had lower propensities of continued childbearing because gender equality was not yet established in people's minds and in practice; the fathers who used the leave may have met major resistance, not least from employers. This pressure may have induced lower fertility. Conversely, the effect may be that fathers using leave may have greater risks of continued childbearing if gender equality is well established in the minds of people but could not earlier be converted into practice because of lack of policies. These general expectations may play out differently in the three countries.

We expect that the more radical shift in policy in Iceland will lead to a more radical change than with the gradual interventions in Norway and Sweden; we therefore expect a stronger association with childbearing from the introduction of the father's quota in Iceland. We expect this effect for both the second and third child propensity, especially as fertility has, until recently, been high in Iceland, and we expect usage up to the quota to be most strongly correlated with childbearing. The association is also likely to be positive and strongest at the beginning of the time when the policy is in effect. Iceland introduced parental leave (and a father's quota) later than the other Nordic countries and at a time when the rest of Icelandic society scored high on gender equality, for example, regarding female labor force participation (Garðarsdóttir 2008). For Norway, with a more ambivalent family policy over a longer period, we expect differences in childbearing depending on fathers' leave use to be relatively strong but 
weaker when fathers' leave use becomes common. Few fathers used the leave before the quota was introduced even though, unlike their Icelandic counterparts, they could do so. The association is expected to be strongest for second births because of the twochild norm, and we expect use up to the quota to be most important. As in Iceland, few fathers in Norway use more leave, and these fathers will probably have to face obstacles at work and negative comments in general.

In Sweden, however, fathers have used leave for the longest period of time, and the potential impact of the quota is less clear. Here, fathers often use longer leave than the quota, but while in the two other countries parental leave must be taken in continual blocks, the Swedish system allows the father to spread out parental leave over time and to use it very flexibly. We therefore expect to see more similarity in Sweden between fathers who use up to the quota and those who use more than the quota. We expect a clear distinction between using and nonusing fathers, but the norm of fathers' childcare involvement is so strong that a substantial group of the nonusers are probably engaged in childcare without using parental leave benefit (for example self-employed men, shift workers, students, and unemployed men who can spend a lot of time at home). As it is common to have a second child, the association is expected to be strong for the propensity of a second child, while the decision about a third child may be guided by other factors, including more traditional familialism. As fathers have used leave for a long time in Sweden, we expect the association to be stable over our study period.

\section{Data and methods}

We use data from the national population registers, which cover the whole population. Each individual is identified by a unique identification number. This allows us to link data from different administrative registers, and we have constructed data sets that contain childbearing histories and longitudinal individual information on civil status and education. We also have information on each parent's country of birth. Most importantly, we have information on the parents' parental leave use. The data covers a period of 15 years; 2001-2009 for Iceland, 1994-2007 for Norway, and 1995-2009 for Sweden - that is, we cover most of the period when the father's quotas have been in place in these countries.

To examine the association between fathers' use of parental leave and continued childbearing, we make use of parents' exposure times to childbearing. We model continued childbearing with event history analysis and estimate the relationship between the father's leave use for the parent's first or second child (as the case may be), and the propensity of having a next-order child. We measure parental leave use for 18 months from birth and exclude cases with births within this time. Overall, in all the 
countries, $5 \%$ to $7 \%$ of couples with one child and fewer among the couples with two children, were excluded. We chose to measure a period of 18 months, as leave is between 9 and 16 months long in the three countries. However, especially in the flexible Swedish system, some spells of fathers' leave are likely to happen later. Our argument for not measuring leave for longer than 18 months is to avoid excluding too many second and third births that may occur during the measured leave period. The first 18 months after birth is also the period when childrearing is most time-intensive and demanding, requiring much devotion. Fathers' leave use is grouped into three categories: (1) no use, (2) use up to the quota, and (3) use longer than the quota, where the length of leave in the last two categories depends on country and time period. Again, this choice is to facilitate comparisons and to capture the distinctions between different gender and parenting norms underlying the quota and the more egalitarian sharing of parental leave. As the leave is of varying length in the three countries, the same number of days may actually indicate different patterns. For example, a father's leave longer than the quota in Norway is often within the quota in Iceland. The same length may thus indicate going beyond the norm and expectation in one country but remaining within the policy norm in the other countries. The leave length influences the amount of leave mothers can use only if it is over the quota. We follow parents that had their first or second common child, excluding multiple births; births abroad; and adoptions. We censor a record if the parents split up or emigrate, or if a parent or the child dies We follow couples to a subsequent birth for a maximum of ten years from a previous birth or to the end of the analyzed period. The estimated risks reflect both the timing and the quantum of a second or third birth. Second and third births are estimated in separate analyses. As we follow only intact couples, we exclude second- and thirdorder births in new unions. Births in such unions may be differently motivated than births within the same unions (Vikat, Thomson, and Hoem 1999). By excluding them we obtain more homogenous groups in all countries. We control for several background variables, including age of the parents, time period, civil status, education categorized according to the International Standard Classification of Education (ISCE), and both parents' country of birth. Age of the youngest child is the exposure time, starting when the child turns 18 months old. Given the high rate of cohabitation without marriage in all three countries, we select parents who are either married or cohabiting at the time of birth or in the year after to account for possible lags in the civil registration system (Thomson and Eriksson 2013). Marriage here is likely to indicate union stability and, to some extent, stronger familial values. It is not certain that marriage in the Nordic countries represents traditional values (see Duvander 1999; Strandell 2017; OhlssonWijk, Brandén, and Duvander 2018), but it represents a serious intention to stay together. Thus, the selection into marriage probably influences continued childbearing. 
A missing consideration is the influence of workplace characteristics on the sharing of parental leave, especially its influence on fathers' leave (Haas and Hwang 2007). Fathers' leave use is likely to be restricted in some jobs, in particular for selfemployment and highly competitive jobs, while use is facilitated in jobs with stable conditions and autonomous tasks. Unfortunately, such information is not available in our data. Fathers selecting into leave and different lengths of leave are probably influenced by the workplace, individual family orientations, couple negotiations. and normative expectations (see, for example, Duvander 2014).

\section{Results}

As seen in Table 1, when we observe Icelandic fathers 18 months after the birth of their child, a major share have used parental leave, and almost a fifth have used more than the quota. In Norway, by contrast, just over half have used some leave over this period, and less than a fifth have used more than the quota. Sweden has the largest spread in use. In this country, approximately a third of fathers have used no leave during the first 18 months, just over a third have used up to the quota, and just less than a third have used more than the quota. It appears that the fathers' parental leave use is more concentrated at the quota in Iceland and Norway than in Sweden. Again, these are not final numbers on fathers' use; some fathers, especially in Sweden, use leave later than the child's first 18 months.

Regarding the sociodemographic characteristics of our country samples, we find that in all countries it is common to marry between the first and the second child and that more parents marry in Norway than in the other two countries. The categorization of educational level indicates that Icelandic parents more often have either a higher or lower level of education compared to Norwegian and Swedish parents. The share of parents born abroad is largest in Sweden and smallest in Iceland. The mean age at having a first and a second birth does not differ substantially between the countries.

In Table 2 we present the results of our analysis as relative risks of a second birth. We are primarily interested in the association with fathers' leave use. In all countries, we find that couples in which the father takes parental leave after the first child have a higher risk of having a second child than couples in which the father takes no leave. However, there are some substantial country differences in the level of intensity with respect to the length of the fathers' leave and the propensity to have a second child. For Iceland, we see that with an increasing fathers' leave length the second-birth risk increases, and when fathers use more than the quota, the propensity of a second child is higher than if fathers use only up to the quota. The relative risk is 1.30 compared to the reference group of nonusers. For Norway the pattern is a reversed U-shape. Couples in 
which the father uses up to the quota have the highest risk of a second child, even if differences are not as large as in Iceland. When the father uses more than the quota, the risk is somewhat lower, but not at the level of couples in which the father uses no leave. For Sweden it seems to make a difference whether the father uses leave or not, but we find no difference between couples in which the father uses more or less than the quota. Although the risk is elevated for couples in which the father uses leave, the differences are smaller than in the other countries.

\section{Table 2: $\quad$ Risk of second birth of one-child couples. Iceland, Norway, and} Sweden (odds ratios)

\begin{tabular}{|c|c|c|c|c|c|c|}
\hline & \multicolumn{2}{|l|}{ Iceland } & \multicolumn{2}{|l|}{ Norway } & \multicolumn{2}{|l|}{ Sweden } \\
\hline & Estimate & c.i & Estimate & c.i & Estimate & c.i \\
\hline \multicolumn{7}{|c|}{ Father's use of parental leave } \\
\hline No use & 1 & & 1 & & 1 & \\
\hline Up to quota & $1.20^{*}$ & $1.08-1.34$ & $1.16^{\star \star}$ & $1.14-1.19$ & $1.05^{\star \star}$ & $1.04-1.06$ \\
\hline More than quota & $1.30^{\star \star}$ & $1.15-1.46$ & $1.09^{\star \star}$ & $1.06-1.12$ & $1.05^{\star \star}$ & $1.04-1.06$ \\
\hline \multicolumn{7}{|l|}{ Union status at birth } \\
\hline Cohabiting & 1 & & 1 & & 1 & \\
\hline Married & $1.19^{\star \star}$ & $1.13-1.26$ & $1.36^{\star \star}$ & $1.33-1.38$ & $1.13^{\star \star}$ & $1.12-1.14$ \\
\hline \multicolumn{7}{|l|}{ Time period at birth } \\
\hline $1994-1997^{1}$ & & & 1 & & 1 & \\
\hline 1998-2000 & & & 1.01 & $0.98-1.04$ & $1.05^{\star \star}$ & $1.04-1.06$ \\
\hline $2001-2004$ & 1 & & $1.06^{\star \star}$ & $1.03-1.09$ & $1.12^{\star \star}$ & $1.11-1.13$ \\
\hline $2005-2009^{2}$ & $1.21^{* *}$ & $1.14-1.27$ & $1.15^{\star \star}$ & $1.12-1.18$ & $1.08^{\star *}$ & $1.06-1.09$ \\
\hline \multicolumn{7}{|l|}{ Mother's education } \\
\hline Low & 1.07 & $0.97-1.06$ & $0.84^{\star \star}$ & $0.79-0.88$ & $0.85^{\star \star}$ & $0.83-0.86$ \\
\hline Medium & 1 & & 1 & & 1 & \\
\hline High & $1.10^{*}$ & $1.03-1.18$ & $1.35^{\star \star}$ & $1.32-1.38$ & $1.27^{\star \star}$ & $1.26-1.28$ \\
\hline \multicolumn{7}{|l|}{ Father's education } \\
\hline Low & 0.97 & $0.89-1.06$ & $0.92^{\star \star}$ & $0.88-0.96$ & $0.91^{\star \star}$ & $0.90-0.93$ \\
\hline Medium & 1 & & 1 & & 1 & \\
\hline High & $1.11^{*}$ & & $1.20^{\star \star}$ & $1.17-1.22$ & $1.20^{\star \star}$ & $1.19-1.21$ \\
\hline Immigrant background & & $1.05-1.18$ & & & & \\
\hline None born abroad & 1 & & 1 & & 1 & \\
\hline Father born abroad & 1.00 & $0.85-1.19$ & 1.00 & $0.95-1.05$ & $0.91^{\star \star}$ & $0.90-0.92$ \\
\hline Mother born abroad & $0.80^{\star \star}$ & $0.71-0.90$ & $0.84^{\star \star}$ & $0.80-0.88$ & $0.74^{\star \star}$ & $0.73-0.75$ \\
\hline Both born abroad & $0.64^{\star *}$ & $0.54-0.75$ & $0.92^{\star \star}$ & $0.87-0.97$ & $0.74^{\star \star}$ & $0.73-0.75$ \\
\hline Mother's age & $1.37^{\star *}$ & $1.28-1.47$ & $1.21^{\star *}$ & $1.18-1.25$ & $1.30^{\star \star}$ & $1.29-1.31$ \\
\hline Mother's age sq & $0.99^{* *}$ & $0.99-1.00$ & $1.00^{* \star}$ & $1.00-1.00$ & $0.99^{\star \star}$ & $0.99-0.99$ \\
\hline Father's age & 1.04 & $1.00-1.09$ & $1.08^{\star \star}$ & $1.06-1.10$ & $1.07^{\star \star}$ & $1.07-1.08$ \\
\hline Father's age sq & 1.00 & $1.00-1.00$ & $1.00^{\star \star}$ & $1.00-1.00$ & $1.00^{\star *}$ & $1.00-1.00$ \\
\hline Log likelihood & \multicolumn{2}{|c|}{$-26,166.033$} & \multicolumn{2}{|c|}{-176057.87} & \multicolumn{2}{|c|}{-1496317.6} \\
\hline Number of observations & \multicolumn{2}{|c|}{212,689} & \multicolumn{2}{|c|}{$1,403,207$} & \multicolumn{2}{|c|}{$11,938,958$} \\
\hline
\end{tabular}

Note: ${ }^{*} 0.001{ }^{*} 0.05 .{ }^{1} 1995$ for Sweden. ${ }^{2} 2007$ for Norway. 
In all countries, and especially in Norway, married couples have a higher risk of second births, everything else being equal. The second-birth risk also increases with both the mothers' and fathers' educational levels, and couples in which both the mother and father are native-born have a higher second-birth risk. The risk of a second birth is also higher among older parents, especially depending on the mother's age. The risk of a second birth increased in the 1990s in Norway and Sweden and in the 2000s in Iceland and Norway.

In Table 3 we present the risk of a third birth. Unlike for a second birth, we do not find a higher propensity to have a third child for couples in which the father takes parental leave. Indeed this propensity was quite the contrary. While in Iceland the relationship between the father's leave use and third-birth risk is not statistically significant, in Norway and Sweden the risk of a third birth is lower when the father has used any parental leave, and in both countries it is lowest in cases where the father has used up to the quota but not more. This finding for Norway and Sweden is in line with some earlier studies (Lappegård 2010), but not with all (see Duvander, Lappegård, and Andersson 2010). This difference will be further discussed in the Discussion section below.

The associations between the control variables and third-birth risks are generally similar to those with second-birth risks. Everything else being equal, there is a higher risk for third births among married couples, and in general higher education leads to higher intensities of third births. For Sweden, the educational gradient for both mothers' and fathers' education is U-shaped; a low and a high education indicates somewhat higher third birth risk than a medium education. In Iceland, having two foreign-born parents indicates a lower third-birth risk, while the opposite is true in Norway and Sweden. Especially in Iceland, older mothers have a higher third-birth risk, but this is also the case in Norway and in Sweden. Third-birth risks decline when the father's age rises. The third-birth risk is higher in the last period of the 2000s in Iceland and Norway, but it appears to be in decline since the 1990s in Sweden.

Fathers' use of paid parental leave has increased over time in all three countries, and to understand the potentially changing associations over time we investigate interactions between the time period and fathers' leave use. Table 4 presents the interactions for second-birth risk. It is clear that for Iceland the positive association is strong immediately after the introduction of the parental leave policy, while it is much weaker in the following five-year period. For Norway, we find a reversed U-shaped pattern for all periods, where couples with fathers using up to the quota have the highest second-birth risks in all periods. As we have mentioned, the quota was extended in steps between 2005 and 2014, which influences the last period in this study (2005 to 2009). During this period the quota users seem to have an elevated propensity of a second child. For Sweden, we find that the risk of a second birth is higher in all periods 
for couples in which the father has used some leave, and especially so in the final period, but there is no sharp distinction between quota-users and those who used more.

Table 3: Risk of third birth of two-child couples. Iceland, Norway, and Sweden (odds ratios)

\begin{tabular}{|c|c|c|c|c|c|c|}
\hline & \multicolumn{2}{|l|}{ Iceland } & \multicolumn{2}{|l|}{ Norway } & \multicolumn{2}{|l|}{ Sweden } \\
\hline & Estimate & c.i. & Estimate & c.i. & Estimate & c.i. \\
\hline \multicolumn{7}{|c|}{ Father's use of parental leave } \\
\hline No use & 1 & & 1 & & 1 & \\
\hline Up to quota & 0.89 & $0.78-1.02$ & $0.93^{\star *}$ & $0.90-0.96$ & $0.86^{\star \star}$ & $0.84-0.87$ \\
\hline More than quota & 1.01 & $0.87-1.17$ & $0.96^{\star \star}$ & $0.92-1.00$ & $0.95^{\star \star}$ & $0.93-0.97$ \\
\hline \multicolumn{7}{|l|}{ Union status at birth } \\
\hline Cohabiting & 1 & & 1 & & 1 & \\
\hline Married & $1.13^{\star \star}$ & $1.05-1.21$ & $1.20^{\star \star}$ & $1.16-1.25$ & $1.28^{\star \star}$ & $1.25-1.30$ \\
\hline \multicolumn{7}{|l|}{ Time period at birth } \\
\hline $1994-1997^{1}$ & & & 1 & & 1 & \\
\hline 1998-2000 & & & $0.95^{\star}$ & $0.91-1.00$ & $0.91^{\star \star}$ & $0.87-0.95$ \\
\hline $2001-2004$ & 1 & & 1.00 & $0.96-1.04$ & 0.99 & $0.95-1.03$ \\
\hline $2005-2009^{2}$ & $1.23^{\star *}$ & $1.15-1.33$ & $1.07^{\star}$ & $1.02-1.11$ & $0.95^{*}$ & $0.92-0.99$ \\
\hline \multicolumn{7}{|l|}{ Mother's education } \\
\hline Low & 1.02 & $0.91-1.15$ & 1.02 & $0.95-1.09$ & $1.10^{\star \star}$ & $1.06-1.13$ \\
\hline Medium & 1 & & 1 & & 1 & \\
\hline High & $1.18^{\star \star}$ & $1.08-1.28$ & $1.54^{\star \star}$ & $1.48-1.59$ & $1.51^{\star \star}$ & $1.48-1.54$ \\
\hline \multicolumn{7}{|l|}{ Father's education } \\
\hline Low & 0.94 & $0.84-1.05$ & 1.02 & $0.95-1.08$ & $1.06^{\star *}$ & $1.03-1.09$ \\
\hline Medium & 1 & & 1 & & 1 & \\
\hline High & $1.12^{*}$ & $1.03-1.21$ & $1.31^{\star *}$ & $1.26-1.35$ & $1.45^{\star \star}$ & $1.42-1.48$ \\
\hline \multicolumn{7}{|l|}{ Immigrant background } \\
\hline None born abroad & 1 & & 1 & & 1 & \\
\hline Father born abroad & 1.12 & $0.88-1.43$ & $1.12^{*}$ & $1.04-1.20$ & $1.15^{\star *}$ & $1.11-1.19$ \\
\hline Mother born abroad & 0.84 & $0.69-1.02$ & 1.00 & $0.92-1.06$ & 0.98 & $0.95-1.02$ \\
\hline Both born abroad & $0.47^{* *}$ & $0.34-0.65$ & $1.22^{\star \star}$ & $1.14-1.31$ & $1.26^{\star \star}$ & $1.22-1.30$ \\
\hline Mother's age & $1.36^{\star *}$ & $1.22-1.52$ & $1.05^{\star}$ & $1.00-1.10$ & $1.03^{*}$ & $1.00-1.06$ \\
\hline Mothers' age sq & $0.99^{\star *}$ & $1.00-1.00$ & $1.00^{\star}$ & $1.00-1.00$ & $1.00^{\star *}$ & $1.00-1.00$ \\
\hline Father's age & 0.97 & $0.90-1.03$ & $0.95^{\star \star}$ & $0.92-0.98$ & $0.93^{\star \star}$ & $0.91-0.94$ \\
\hline Father's age sq & 1.00 & $1.00-1.00$ & 1.00 & $1.00-1.00$ & $1.00^{\star \star}$ & $1.00-1.00$ \\
\hline Log likelihood & $-19,169.286$ & & $-104,172.73$ & & $-370,726.61$ & \\
\hline Number of observations & 371,387 & & $3,151,932$ & & $15,227,927$ & \\
\hline
\end{tabular}

Note: ** $0.001{ }^{*} 0.05 .{ }^{1} 1995$ for Sweden. ${ }^{2} 2007$ for Norway. 
Table 4: $\quad$ Risk of second birth of one-child couples, Iceland, Norway, and Sweden. Interactions between father's use of parental leave and time period (odds ratios)

\begin{tabular}{|c|c|c|c|c|c|c|c|c|c|c|c|c|}
\hline & \multicolumn{4}{|c|}{ Iceland } & \multicolumn{4}{|c|}{ Norway } & \multicolumn{4}{|c|}{ Sweden } \\
\hline & $\begin{array}{l}1994- \\
1997\end{array}$ & $\begin{array}{l}1998- \\
2000\end{array}$ & $\begin{array}{l}2001- \\
2004\end{array}$ & $\begin{array}{l}2005- \\
2009\end{array}$ & $\begin{array}{l}1994- \\
1997\end{array}$ & $\begin{array}{l}1998- \\
2000\end{array}$ & $\begin{array}{l}2001- \\
2004\end{array}$ & $\begin{array}{l}2005- \\
2009\end{array}$ & $\begin{array}{l}1994- \\
1997\end{array}$ & $\begin{array}{l}1998- \\
2000\end{array}$ & $\begin{array}{l}2001- \\
2004\end{array}$ & $\begin{array}{l}2005- \\
2009\end{array}$ \\
\hline No use & & & 1 & 1 & 1 & 1 & 1 & 1 & 1 & 1 & 1 & 1 \\
\hline \multicolumn{3}{|l|}{ Up to quota } & 1.44 & 0.97 & 1.18 & 1.10 & 1.15 & 1.23 & 1.06 & 1.02 & 1.06 & 1.07 \\
\hline \multicolumn{3}{|c|}{ More than quota } & 1.46 & 1.11 & 1.10 & 1.04 & 1.06 & 1.13 & 1.03 & 1.02 & 1.05 & 1.10 \\
\hline
\end{tabular}

Note: Controlled for union status at birth, mother's/father's age, education, and immigrant background, and number of children. See Table A-1 in the Appendix for details.

In Table 5 we present the results of the same interaction between the time period and fathers' leave use for the risk of a third birth. For Iceland we find a lower risk of a third birth in both of the measured periods. For Norway the pattern is slightly U-shaped in all periods, but especially in the 1990s we find that fathers using up to the quota have lower risks of a third birth. For Sweden, the pattern is also U-shaped for all periods, more strongly so than for Norway. It is thus the couples in which the fathers use up to the quota that have the lowest third-birth risks over the whole 15-year period. The propensity of a third birth is almost at the same level for fathers using more than the quota as for nonusers. This indicates that a heterogeneous group of parents continues to a third child, as is perhaps also seen in the U-shaped association with educational level of mother and father (Table 3).

Table 5: $\quad$ Risk of third birth of two-child couples, Iceland, Norway, and Sweden. Interactions between father's use of parental leave and time period (odds ratios)

\begin{tabular}{|c|c|c|c|c|c|c|c|c|c|c|c|c|}
\hline & \multicolumn{4}{|l|}{ Iceland } & \multicolumn{4}{|c|}{ Norway } & \multicolumn{4}{|c|}{ Sweden } \\
\hline & $\begin{array}{l}1994- \\
1997\end{array}$ & $\begin{array}{l}1998- \\
2000\end{array}$ & $\begin{array}{l}2001- \\
2004\end{array}$ & $\begin{array}{l}2005- \\
2009\end{array}$ & $\begin{array}{l}1994- \\
1997\end{array}$ & $\begin{array}{l}1998- \\
2000\end{array}$ & $\begin{array}{l}2001- \\
2004\end{array}$ & $\begin{array}{l}2005- \\
2009\end{array}$ & $\begin{array}{l}1994- \\
1997\end{array}$ & $\begin{array}{l}1998- \\
2000\end{array}$ & $\begin{array}{l}2001- \\
2004\end{array}$ & $\begin{array}{l}2005- \\
2009\end{array}$ \\
\hline \multicolumn{3}{|l|}{ No use } & 1 & 1 & 1 & 1 & 1 & 1 & 1 & 1 & 1 & 1 \\
\hline \multicolumn{3}{|l|}{ Up to quota } & 0.88 & 0.92 & 0.91 & 0.88 & 0.94 & 0.98 & 0.86 & 0.85 & 0.87 & 0.86 \\
\hline \multicolumn{3}{|c|}{ More than quota } & 0.98 & 1.04 & 0.95 & 0.92 & 0.94 & 1.03 & 0.94 & 0.95 & 0.96 & 0.95 \\
\hline
\end{tabular}

Note: Controlled for union status at birth, mother's/father's age, education, and immigrant background, and number of children. See Table A-2 in the Appendix for details.

\section{Discussion}

This study takes as its starting point the widely held theoretical assumption that in postindustrial societies, gender equality in the family is associated with high fertility levels. 
However, while much research deals with this relationship at the macro level, there are very few studies that scrutinize it at the micro level. Furthermore, there are hardly any studies that have investigated this association and distinguish between gender-equal behavior that conforms to the policy setting and gender-egalitarian behavior that goes beyond the policy-ascribed norm. We analyze the association between fathers' leave use and continued childbearing in three Nordic countries, and we differentiate between fathers who use no parental leave, those who use only up to the quota (i.e., the part reserved exclusively for fathers), and those who use more parental leave (i.e., those who used part of the leave that the mother and father can share).

Comparing the relationship between the extent of fathers' leave and subsequent childbearing in three similar countries enables us to draw conclusions on the importance of various policy arrangements and gender-egalitarian behavior. Findings from such comparative studies supply sound evidence for policymakers and improve the knowledge base for population-related and gender-egalitarian-oriented policy formulation (e.g., Neyer and Andersson 2008). We chose Iceland, Norway, and Sweden for our study as these countries all have quotas, and the fathers there are using them to a considerable degree. Both Denmark and Finland would have been candidates for comparison, but as these countries have not had a long and consistent period of quotas, we considered them too different for a 'most similar analysis.'

Our main theoretical prediction that fathers who use parental leave have higher propensities of continued childbearing depends on parity. Starting with the transition to the second child, it is clear that, in the cases in which the father uses parental leave, the propensity for a second child is higher in all three countries. This holds regardless of whether the father uses only up to the quota or uses more than the quota. For Iceland and Norway, we expected that fathers who use only up to the quota would have the highest propensity to have a second child, mainly because of the construction of the policies, the timing of their introduction, and the established parental-leave and childbearing behavior. As expected, in Norway, couples in which fathers use up to the quota (but not more) have the highest risk of a second child. However, we find that in Iceland, fathers who use more than the quota have an even higher propensity to have a second child than fathers who use only up to the quota. The finding may seem puzzling, but it points to the need to pay attention to the details within leave systems that may appear very similar. Icelandic parental leave is shorter than in the other countries, which may set the fathers who use more than the quota apart as more dedicated to gender equality and family engagement. It may also be that the association between gender-egalitarian sharing of parental leave and second-birth fertility is stronger in Iceland because of the more radical gender-equal parental leave system in Iceland, and because gender equality was already an established idea in the rest of the society when the gender-equal parental leave was introduced. For Sweden, where fathers have 
commonly used parental leave for a long time, we expected to find no pronounced differences between the childbearing intensity of fathers who use only up to the quota and those who use more than the quota. This expectation was confirmed by our data, as the distinction was rather between fathers who used parental leave and those who did not.

Regarding the propensity of a third birth, we expected to find a weaker association in all countries, which was also confirmed in the analyses. There is no clear association between the father's leave use and the risk of a third birth in Iceland, but quite unexpectedly in both Norway and Sweden, fathers who use the leave seem to have a lower risk of a third birth - especially when fathers use the leave up to the quota. It is thus those who follow the conventional pattern of use that have the lowest risk of a third child. It may be that parents who decide to have three children have different family, work, and egalitarian orientations than those who have two children, and, in addition, going on parental leave and caring for two children is also more demanding than taking leave and caring for one child. Using leave only up to the quota may not be a sufficient commitment of the father to engage in childrearing to generate a third child. Fathers' quota use may facilitate the mothers' engagement in the labor market and/or allow her more free time but may not necessarily lead to more children.

Furthermore, the results of our study provide an additional proof of how careful one must be in universalizing findings regarding the association between family policies and fertility. Ostensibly, the results of our study for third births contrast with those of an earlier study on fathers' uptake of parental leave and third-births risks in Norway between 1993-2003 and in Sweden between 1988-1999 (Duvander, Lappegård, and Andersson 2010). Duvander, Lappegård, and Andersson (2010) find that, except for very long leaves, fathers' use of parental leave with the second child increases a couple's propensity to have a third child. Some differences in measurements are the likely reasons for the different results. The study by Duvander, Lappegard, and Andersson (2010) could use only a proxy for parental leave duration, namely, the parental leave benefit as a share of a person's income during the year of use. As there is a ceiling to the benefit, this may have distorted the results somewhat. Since the data on income (earned and parental benefit) were annual, they selected only couples with births in January. In the current study, we were able to use categorized days of leave and could use full years of births. We could also distinguish between fathers who were on leave only up to the quota and those who took parental leave longer than the quota. We included parents born abroad; Duvander, Lappegård, and Andersson (2010) excluded them. Furthermore, the earlier study followed parental leave use for two years, while this study followed leave for 18 months. They therefore included a larger share of both Swedish and Norwegian fathers' use, but they also excluded more births within this time period. In the earlier study, $86 \%$ of Swedish and $70 \%$ of Norwegian 
first-time fathers were leave-users, compared to $70 \%$ of Swedish and $54 \%$ of Norwegian first-time fathers in this study. This indicates that many fathers in both countries use leave later than the first 18 months. The earlier study had the benefit of controlling for mothers' use and earnings, which we could not. Part of the difference may also be caused by a change in the associations over time; the time period covered in the present study is more recent and longer. There are thus several study differences that can explain the different results. The main conclusion is that while the results for second-birth risks are consistent across these studies, third-birth intensities are sensitive to measurement issues and should be further investigated.

It is important to highlight that the families in which the father uses leave only up to the quota are less close to achieving the concept of gender equality, as the mother still takes the lion's share of leave. Taking the quota will not change a gender-based division of domestic work, but it will create a new point of reference for negotiations in the private sphere. For all countries, this now seems to be associated with a faster pace toward a second child. In Iceland, the diffusion process of sharing childcare may have come furthest in a very short time, perhaps in line with Esping-Andersen and Billari's proposition of more rapid changes in less-stratified societies (2015).

Overall, the question remains as to whether fathers' leave use indicates a process toward a complete gender revolution and whether this will lead to higher fertility, as theory suggests. Our analysis on the individual level suggests that the diffusion of gender equality is not uniform and that even if gender equality has penetrated all levels of society as a social norm, it does not lead to a uniform association between the sharing of parental leave and continued childbearing.

\section{Acknowledgements}

The research leading to these results has received funding from the Nordic Family Policy and Demographic consequences (NORDiC), supported by the Research Council of Norway (217915/F10); European Union's Seventh Framework Programme (FP7/2007-2013) under grant agreement no. 320116 for the research project FamiliesAndSocieties; Swedish Research Council (Vetenskapsrådet) via the Linnaeus Center on Social Policy; and Family Dynamics in Europe (SPaDE), grant 349-20078701 . 


\section{References}

Anderson, T. and Kohler, H.-P. (2015). Low fertility, socioeconomic development, and gender equity. Population and Development Review 41(3): 381-407. doi:10.1111/j.1728-4457.2015.00065.x.

Andersson, G., Rønsen, M., Knudsen, L., Lappegård, T., Neyer, G., Skrede, K., Teschner, K., and Vikat, A. (2009). Cohort fertility patterns in the Nordic countries. Demographic Research 20(14): 313-352. doi:10.4054/DemRes.2009. 20.14 .

Ang, X.L. (2015). The effects of cash transfer fertility incentives and parental leave benefits on fertility and labor supply: Evidence from two natural experiments. Journal of Family and Economic Issues 36(2): 263-288. doi:10.1007/s10834014-9394-3.

Arnalds, A.A., Eydal, G.B., and Gíslason, I.G. (2011). Equal rights to paid parental leave and caring father: The case of Iceland. Icelandic Review of Politics and Administration 9(2): 323-344. doi:10.13177/irpa.a.2013.9.2.4.

Billingsley, S. and Ferrarini, T. (2014). Family policy and fertility intentions in 21 European countries. Journal of Marriage and Family 76(2): 428-445. doi:10.1111/jomf.12097.

Blum, S., Koslowski, A., and Moss, P. (2017). International review of leave policies and research 2017. Leave Network. https://www.leavenetwork.org/fileadmin/ user_upload/k_leavenetwork/annual_reviews/2017_Leave_Review_2017_final2 .pdf.

Cedstrand, S. (2011). Från idé till politisk verklighet: Föräldrapolitiken i Sverige och Danmark. Umeå: Boréa.

Chesnais, J.-C. (1996). Fertility, family, and social policy in contemporary Western Europe. Population and Development Review 22(4): 729-739. doi:10.2307/ 2137807.

Cooke, L.P. (2004). The gendered division of labor and family outcomes in Germany. Journal of Marriage and Family 66(5): 1246-1259. doi:10.1111/j.0022-2445. 2004.00090.x.

Cooke, L.P (2009). Gender equity and fertility in Italy and Spain. Journal of Social Policy 38(1): 123-140. 
Cools, S., Fiva, J.H., and Kirkeboen, L.J. (2015). Causal effects of childcare leave on children and parents. Scandinavian Journal of Economics 117(3): 801-828. doi:10.1111/sjoe.12113.

Cygan-Rehn, K. (2016). Parental leave benefit and differential fertility responses: evidence from a German reform. Journal of Population Economics 29(1): 73103. doi:10.1007/s00148-015-0562-z.

Dahl, G.B., Løken, K.V., and Mogstad, M. (2014). Peer effects in program participation. American Economic Review 104(7): 2049-2074. doi:10.1257/aer. 104.7.2049.

Daly, M. (2000). A fine balance: Women's labour market participation in International comparison. In: Scharpf, F.W. and Schmidt, V.A. (eds.). Welfare and work in open economy, Vol. 2: Diverse responses to common challenges. Oxford: Oxford Scholarship Online. doi:10.1093/0199240922.003.0010.

Dommermuth, L., Hohmann-Marriott, B., and Lappegård, T. (2017). Gender equality in the family and childbearing. Journal of Family Issues 38(3): 1803-1824. doi:10.1177/0192513X15590686.

Duvander, A.-Z. (1999). The transition from cohabitation to marriage: A longitudinal study of the propensity to marry in Sweden in the early 1990s. Journal of Family Issues 20(5): 698-717. doi:10.1177/019251399020005007.

Duvander, A.-Z. (2014). How long should parental leave be? Attitudes to gender equality, family, and work as determinants of women's and men's parental leave in Sweden. Journal of Family Issues 35 (7): 909-926

Duvander, A.-Z. and Andersson, G. (2006). Gender equality and fertility in Sweden: A study on the impact of the father's uptake of parental leave on continued childbearing. Marriage and Family Review 39(1-2): 121-142. doi:10.1300/ J002v39n01_07.

Duvander, A.-Z., Haas, L., and Thalberg, S. (2017). Fathers on leave alone in Sweden: Toward more equal parenthood? In: O'Brien, M. and Wall, K. (eds.). Comparative perspectives on work-life balance and gender equality: Fathers on leave alone. Cham: Springer: 125-146. doi:10.1007/978-3-319-42970-0_8.

Duvander, A.-Z. and Johansson, M. (2012). What are the effects of reforms promoting fathers' parental leave use? Journal of European Social Policy 22(3): 319-330. doi:10.1177/0958928712440201. 
Duvander, A.-Z. and Johansson, M. (2015). Parental leave use for different fathers: A study of the impact of three Swedish parental leave reforms. In: Eydal, G.B. and Rostgaard, T. (eds.). Fatherhood in the Nordic welfare states: Comparing care policies and practice. Bristol: Policy Press: 349-374. doi:10.1332/policypress/ 9781447310471.003.0016.

Duvander, A.-Z., Lappegård, T., and Andersson, G. (2010). Family policy and fertility: Fathers' and mothers' use of parental leave and continued childbearing in Norway and Sweden. Journal of European Social Policy 20(1): 45-57. doi:10.1177/0958928709352541.

England, P. (2010). The gender revolution: Uneven and stalled. Gender and Society 24(2): 149-166. doi:10.1177/0891243210361475.

Esping-Andersen, G. and Billari, F.C. (2015). Re-theorizing family demographics. Population and Development Review 41(1): 1-31. doi:10.1111/j.1728-4457.20 15.00024.x.

Eydal, G.B. and Gíslason, I. (2015). Caring fathers and parental leave in prosperous times and times of crisis: The case of Iceland. In: Eydal, G.B. and Rostgaard, T. (eds.). Fatherhood in the Nordic welfare states: Comparing care policies and practice. Bristol: Policy Press: 325-348. doi:10.1332/policypress/97814473 10471.003.0015.

Garðarsdóttir, Ó. (2008). Fertility trends in Iceland in a Nordic comparative perspective. In: Eydal, G.B. and Gíslason, I.V. (eds.). Equal rights to earn and care: Parental leave in Iceland. Reykjavík: Félagsvísindastofnun Íslands: 4564.

Gauthier, A.H. and Hatzius, J. (1997). Family benefits and fertility: An econometric analysis. Population Studies 51(3): 295-306. doi:10.1080/003247203100015 0066.

Gíslason, I. (2017). Fathers on leave alone in Iceland: Normal paternal behaviour? In: O'Brien, M. and Wall, K. (eds.). Comparative perspectives on work-life balance and gender equality: Fathers on leave alone. Cham: Springer: 147-162. doi:10.1007/978-3-319-42970-0_9.

Goldscheider, F., Bernhardt, E., and Brandén, M. (2013). Domestic gender equality and childbearing in Sweden. Demographic Research 29(4): 1097-1126. doi:10.4054/ DemRes.2013.29.40. 
Goldscheider, F., Bernhardt, E., and Lappegård, T. (2015). The gender revolution: A framework for understanding changing family and demographic behaviour. Population and Development Review 41(2): 207-239. doi:10.1111/j.17284457.2015.00045.x.

Haas, L. and Hwang, C.P. (2007). Gender and organizational culture correlates of companies' responsiveness to fathers in Sweden. Gender and Society 21(1): 5279. doi: $10.1177 / 0891243206295091$.

Hakovirta, M., Haataja, A., Eydal, G.B., and Rostgaard, T. (2015). Fathers' right to family cash benefits in the Nordic countries. In: Eydal, G.B. and Rostgaard, T. (eds.). Fatherhood in the Nordic welfare states: Comparing care policies and practice. Bristol: Policy Press: 79-102. doi:10.1332/policypress/978144731047 1.003.0004.

Hochschild, A.R. (1989). The second shift: Working families and the revolution at home. New York: Viking.

Hook, J.L. (2006). Care in context: Men's unpaid work in 20 countries, 1965-2003. American Sociological Review 71(4): 639-660. doi:10.1177/0003122406071 00406.

Kalwij, A. (2010). The impact of family policy expenditure on fertility in Western Europe. Demography 47(2): 503-519. doi:10.2139/ssrn.1508427.

Kamerman, S. and Kahn, A. (1978). Family policy: Government and families in fourteen countries. New York: Columbia University Press.

Kato, T., Kumamaru, H., and Fukuda, S. (2019). Men's participation in childcare and housework and parity progression: A Japanese population-based study. Asian Population Studies 14(3): 290-309. doi:10.1080/17441730.2018.1523977.

Kotsadam, A. and Finseraas, H. (2013). Causal effects of parental leave on adolescents' household work. Social Forces 92(1): 329-351. doi:10.1093/sf/sot044.

Kvande, E. and Brandth, B. (2017). Fathers on leave alone in Norway: Changes and continuities. In: O'Brien, M. and Wall, K. (eds.). Comparative perspectives on work-life balance and gender equality: Fathers on leave alone. Cham: Springer: 29-44. doi:10.1007/978-3-319-42970-0_3.

Lalive, R. and Zweimuller, J. (2009). How does parental leave affect fertility and return to work? Evidence from two natural experiments. The Quarterly Journal of Economics 124(3): 1363-1402. doi:10.1162/qjec.2009.124.3.1363. 
Lappegård, T. (2010). Family policies and fertility in Norway. European Journal of Population 26(1): 99-116. doi:10.1007/s10680-009-9190-1.

Luci-Greulich, A. and Thévenon, O. (2013). The impact of family policy on fertility trends in developed countries. European Journal of Population 29(4): 387-416. doi:10.1007/s10680-013-9295-4.

Matysiak, A. and Szalma, I. (2014). Effects of parental leave policies on second birth risks and women's employment entry. Population 69(4): 599-636. doi:10.3917/ popu.1404.0659.

McDonald, P. (2000). Gender equity in theories of fertility transition. Population and Development Review 26(3): 427-439. doi:10.1111/j.1728-4457.2000.00427.x.

McDonald, P. (2013). Social foundation for explaining fertility: Gender equity. Demographic Research 28(34): 981-994. doi:10.4054/DemRes.2013.28.34.

Nagase, N. and Brinton, M. (2017). The gender division of labor and second births: Labor market institutions and fertility in Japan. Demographic Research 36(11): 339-370. doi:10.4054/DemRes.2017.36.11.

Neyer, G. (2003). Family policies and low fertility in Western Europe. Journal of Population and Social Security (Population) S1: 46-93. http://www.ipss.go.jp/ webj-ad/WebJournal.files/population/2003_6/3.Neyer.pdf.

Neyer, G. and Andersson, G. (2008). Consequences of family policies on childbearing behaviour: Effects or artefacts? Population and Development Review 34(4): 699-724. doi:10.1111/j.1728-4457.2008.00246.x.

Neyer, G., Lappegård, T., and Vignoli, D. (2013). Gender equality and fertility: Which equality matters? European Journal of Population 29(3): 245-272. doi:10.1007/ s10680-013-9292-7.

Ohlsson-Wijk, S., Brandén, M., and Duvander, A.-Z. (2018). Committing to marriage? The role of marriage attitudes and gender equality among young cohabiters in Sweden. Stockholm: Department of Sociology, Stockholm University (Stockholm Research Reports in Demography 2018:11).

Oláh, L.Sz. (2003). Gendering fertility: Second births in Sweden and Hungary. Population Research and Policy Review 22(2): 171-200. doi:10.1023/A:10250 89031871.

Oláh, L.Sz. and Bernhardt, E. (2008). Sweden: Combining childbearing and gender equality. Demographic Research 19(28): 1105-1144. doi:10.4054/DemRes.20 08.19.28. 
Rege, M. and Solli, I. (2013). The impact of childcare leave on fathers' future earnings. Demography 50(6): 2255-2277. doi:10.1007/s13524-013-0233-1.

Sigurdardóttir, H.M. and Garðarsdóttir, Ó. (2018). Backlash in gender equality? Father's parental leave during a time of economic crisis. Journal of European Social Policy 28(4): 342-356. doi:10.1177/0958928717739243.

Stanfors, M. and Goldscheider, F. (2017). The forest and the trees: Industrialization, demographic change, and the ongoing gender revolution in Sweden and the United States 1870-2010. Demographic Research 36(6): 173-226. doi:10.4054/ DemRes.2017.36.6.

Stier, H., Lewin-Epstein, N., and Braun, M. (2001).Welfare regimes, family-supportive policies and women's employment along the life-course. American Journal of Sociology 106(6): 1731-1760. doi:10.1086/321302.

Strandell, J. (2017). Increasing marriage rates despite high individualization: Understanding the role of internal reference in Swedish marriage discourse. Cultural Sociology 12(1): 75-95. doi:10.1177/1749975517722476.

Swedish Social Insurance Agency (2012). Föräldrapenning: Analys av användandet 1974-2011. Stockholm: Försäkringskassan (Socialförsäkringsrapport 2012:9).

Thévenon, O. and Gauthier, A.H. (2011). Family policies in developed countries: A 'fertility-booster' with side-effects. Community, Work and Family 14(2): 197216. doi:10.1080/13668803.2011.571400.

Thomson, E. and Eriksson, H. (2013). Register-based estimates of parents' coresidence in Sweden, 1969-2007. Demographic Research 29(42): 1153-1186. doi:10.405 4/DemRes.2013.29.42.

Torr, B. and Short, S. (2004). Second births and the second shift: A research note on gender equity and fertility. Population and Development Review 30(1): 109130. doi:10.1111/j.1728-4457.2004.00005.x.

Vikat, A., Thomson, E., and Hoem, J.M. (1999). Stepfamily fertility in contemporary Sweden: The impact of childbearing before the current union. Population Studies 53(2): 211-225. doi:10.1080/00324720308082. 
Duvander et al.: Parental leave policies and continued childbearing in Iceland, Norway, and Sweden

\section{Appendix}

Table A-1: Risk of second birth of one-child couples, Iceland, Norway, and Sweden. Odds ratio. Including interaction between father's use of parental leave and time period

\begin{tabular}{|c|c|c|c|c|c|c|}
\hline & \multicolumn{2}{|l|}{ Iceland } & \multicolumn{2}{|l|}{ Norway } & \multicolumn{2}{|l|}{ Sweden } \\
\hline & Estimate & c.i. & Estimate & c.i. & Estimate & c.i. \\
\hline \multicolumn{7}{|l|}{$\begin{array}{l}\text { Father's use of parental leave* } \\
\text { time period at birth }\end{array}$} \\
\hline No use*1994-1997 & & & 1 & & 1 & \\
\hline Up to quota*1994-1997 & & & $1.18^{\star \star}$ & $1.13-1.23$ & $1.06^{\star \star}$ & $1.04-1.08$ \\
\hline More than quota*1994-1997 & & & $1.10^{*}$ & $1.05-1.16$ & $1.03^{*}$ & $1.00-1.05$ \\
\hline No use*1998-2000 & & & $1.05^{\star}$ & $1.00-1.09$ & $1.07^{\star \star}$ & $1.05-1.09$ \\
\hline Up to quota*1998-2000 & & & $1.15^{\star \star}$ & $1.10-1.20$ & $1.09^{* *}$ & $1.07-1.11$ \\
\hline More than quota*1998-2000 & & & $1.09^{*}$ & $1.03-1.16$ & $1.09^{* *}$ & $1.07-1.11$ \\
\hline No use ${ }^{\star} 2001-2004$ & 1 & & $1.08^{\star \star}$ & $1.03-1.12$ & $1.11^{\star *}$ & $1.09-1.13$ \\
\hline Up to quota*2001-2004 & $1.44^{* *}$ & $1.24-1.67$ & $1.24^{\star *}$ & $1.19-1.29$ & $1.18^{\star *}$ & $1.16-1.20$ \\
\hline More than quota*2001-2004 & $1.46^{\star *}$ & $1.24-1.72$ & $1.15^{\star \star}$ & $1.09-1.21$ & $1.17^{\star *}$ & $1.15-1.20$ \\
\hline No use*2005-2009 & $1.70^{* *}$ & $1.39-2.10$ & $1.12^{\star \star}$ & $1.08-1.17$ & $1.05^{\star \star}$ & $1.03-1.07$ \\
\hline Up to quota*2005-2009 & $1.65^{\star \star}$ & $1.41-1.92$ & $1.38^{\star \star}$ & $1.32-1.44$ & $1.12^{\star *}$ & $1.10-1.14$ \\
\hline More than quota*2005-2009 & $1.89^{\star \star}$ & $1.60-2.33$ & $1.27^{\star \star}$ & $1.21-1.33$ & $1.15^{\star \star}$ & $1.13-1.17$ \\
\hline Log likelihood & \multicolumn{2}{|l|}{$26,158.64$} & \multicolumn{2}{|c|}{$-1,706,051.9$} & \multicolumn{2}{|c|}{$-1,496,290.2$} \\
\hline Number of observations & \multicolumn{2}{|l|}{371,387} & \multicolumn{2}{|c|}{$3,151,932$} & \multicolumn{2}{|c|}{$11,938,958$} \\
\hline
\end{tabular}

Note: ${ }^{* *} 0.001{ }^{*} 0.05 .{ }^{1} 1995$ for Sweden. ${ }^{2} 2007$ for Norway.

Table A-2: Risk of third birth of two-child couples, Iceland, Norway, and Sweden. Odds ratio. Including interaction between father's use of parental leave and time period

\begin{tabular}{|c|c|c|c|c|c|c|}
\hline & \multicolumn{2}{|l|}{ Iceland } & \multicolumn{2}{|l|}{ Norway } & \multicolumn{2}{|l|}{ Sweden } \\
\hline & Estimate & c.i. & Estimate & c.i. & Estimate & c.i. \\
\hline \multicolumn{7}{|l|}{$\begin{array}{l}\text { Father's use of parental leave } \\
\text { time period at birth }\end{array}$} \\
\hline No use*1994-1997 & & & 1 & & 1 & \\
\hline Up to quota*1994-1997 & & & $0.91^{*}$ & $0.86-0.97$ & $0.86^{\star \star}$ & $0.79-0.93$ \\
\hline More than quota*1994-1997 & & & 0.95 & $0.88-0.99$ & 0.94 & $0.85-1.03$ \\
\hline No use*1998-2000 & & & 0.96 & $0.91-1.02$ & $0.91^{*}$ & $0.86-0.97$ \\
\hline Up to quota*1998-2000 & & & $0.84^{\star \star}$ & $0.82-0.93$ & $0.77^{\star \star}$ & $0.73-0.82$ \\
\hline More than quota*1998-2000 & & & $0.88^{*}$ & $0.81-0.97$ & $0.86^{\star \star}$ & $0.80-0.91$ \\
\hline No use ${ }^{\star} 2001-2004$ & 1 & & 1.00 & $0.94-1.05$ & 0.98 & $0.93-1.04$ \\
\hline Up to quota*2001-2004 & 0.88 & $0.74-1.05$ & $0.94^{*}$ & $0.88-0.99$ & $0.85^{\star *}$ & $0.80-0.90$ \\
\hline More than quota*2001-2004 & 0.98 & $0.81-1.20$ & 0.94 & $0.87-1.01$ & 0.94 & $0.89-1.00$ \\
\hline No use*2005-2009 & 1.19 & $0.92-1.54$ & 1.02 & $0.96-1.08$ & 0.95 & $0.90-1.01$ \\
\hline Up to quota*2005-2009 & 1.09 & $0.91-1.30$ & 1.00 & $0.98-1.07$ & $0.82^{\star *}$ & $0.77-0.87$ \\
\hline More than quota*2005-2009 & 1.24 & $1.01-1.51$ & 1.05 & $0.98-1.14$ & $0.90^{\star *}$ & $0.85-0.96$ \\
\hline Log likelihood & \multicolumn{2}{|c|}{$-19,169.216$} & \multicolumn{2}{|c|}{$-104,170.01$} & \multicolumn{2}{|c|}{$-370,726.23$} \\
\hline Number of observations & \multicolumn{2}{|c|}{371,387} & \multicolumn{2}{|c|}{$3,151,932$} & \multicolumn{2}{|c|}{$15,227,927$} \\
\hline
\end{tabular}

Note: ${ }^{* *} 0.001 * 0.05 .{ }^{1} 1995$ for Sweden. ${ }^{2} 2007$ for Norway. 